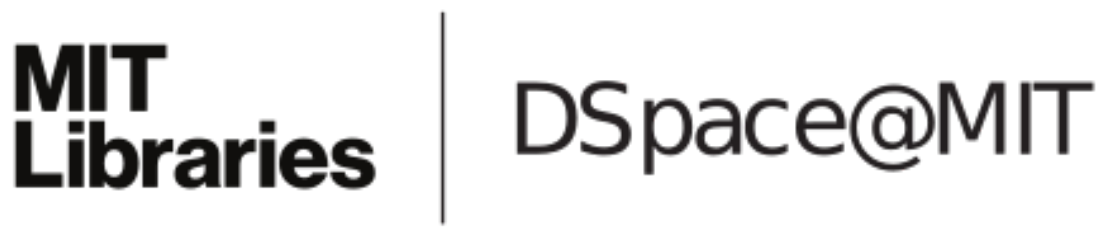

\author{
MIT Open Access Articles
}

\section{Metal-substituted protein MRI contrast agents engineered for enhanced relaxivity and ligand sensitivity}

The MIT Faculty has made this article openly available. Please share how this access benefits you. Your story matters.

Citation: Lelyveld, Victor S. et al. “Metal-Substituted Protein MRI Contrast Agents Engineered for Enhanced Relaxivity and Ligand Sensitivity." Journal of the American Chemical Society (2011) 133 (4), pp 649-651.

As Published: http://dx.doi.org/10.1021/ja107936d

Publisher: American Chemical Society

Persistent URL: http://hdl.handle.net/1721.1/66550

Version: Author's final manuscript: final author's manuscript post peer review, without publisher's formatting or copy editing

Terms of use: Creative Commons Attribution-Noncommercial-Share Alike 3.0 


\title{
Metal-Substituted Protein MRI Contrast Agents Engineered for Enhanced Relaxivity and Ligand Sensitivity
}

\author{
Victor S. Lelyveld ${ }^{\dagger}$, Eric Brustad", Frances H. Arnold", and Alan Jasanoff ${ }^{*}, \dagger, \ddagger, \S$ \\ tDepartment of Biological Engineering, Massachusetts Institute of Technology, 77 Massachusetts \\ Avenue, Cambridge, Massachusetts 02139, United States \\ ¥Department of Brain and Cognitive Sciences, Massachusetts Institute of Technology, 77 \\ Massachusetts Avenue, Cambridge, Massachusetts 02139, United States \\ §Department of Nuclear Science and Engineering, Massachusetts Institute of Technology, 77 \\ Massachusetts Avenue, Cambridge, Massachusetts 02139, United States \\ "Division of Chemistry and Chemical Engineering, California Institute of Technology, Mail Code \\ 210-41, Pasadena, California 91125, United States
}

\begin{abstract}
Engineered metalloproteins constitute a flexible new class of analyte-sensitive molecular imaging agents detectable by magnetic resonance imaging (MRI), but their contrast effects are generally weaker than synthetic agents. To augment the proton relaxivity of agents derived from the heme domain of cytochrome P450 BM3 (BM3h), we formed manganese(III)-containing proteins that have higher electron spin than their native ferric iron counterparts. Metal substitution was achieved by coexpressing BM3h variants with the bacterial heme transporter ChuA in Escherichia coli and supplementing the growth medium with $\mathrm{Mn}^{3+}$-protoporphyrin IX. Manganic BM3h variants exhibited up to 2.6-fold higher $T_{1}$ relaxivities relative to native BM3h at $4.7 \mathrm{~T}$. Application of ChuA-mediated porphyrin substitution to a collection of thermostable chimeric P450 domains resulted in a stable, high-relaxivity BM3h derivative displaying a 63\% relaxivity change upon binding of arachidonic acid, a natural ligand for the P450 enzyme and an important component of biological signaling pathways. This work demonstrates that protein-based MRI sensors with robust ligand sensitivity may be created with ease by including metal substitution among the toolkit of methods available to the protein engineer.
\end{abstract}

To be useful in the laboratory or clinic, responsive MRI contrast agents for molecular imaging must display large ${ }^{1} \mathrm{H}$ NMR relaxivity changes at field strengths above $1 \mathrm{~T} .{ }^{1,2}$ This requirement presents a unique challenge for metalloprotein-based contrast agents, which are limited by the natural magnetic and solvent interaction parameters of protein-coordinated transition metals ${ }^{3,4}$ or biomineralized deposits. ${ }^{5}$ A class of engineered ligand-responsive contrast agents recently generated by us through directed evolution of the heme domain of Bacillus megaterium cytochrome P450 BM3 (BM3h) ${ }^{6}$ exemplifies this problem. Although BM3h-based neurotransmitter sensors were shown to detect dopamine release in living rat brains, the initial experiments were relatively insensitive because of the low longitudinal $\left(T_{1}\right)$ relaxivity of these proteins $\left(r_{1} \approx 1 \mathrm{mM}^{-1} \mathrm{~s}^{-1}\right.$ at $22{ }^{\circ} \mathrm{C}$ and $\left.4.7 \mathrm{~T}\right)$. BM3h derivatives with improved relaxivity could offer better analyte sensitivity and reduced potential for

\footnotetext{
(c) 2010 American Chemical Society

*Corresponding Author: jasanoff@mit.edu.

Supporting Information. Detailed methods, thermostable chimera composition, thermostability data, optical absorbance data, and additional relaxivity measurements. This material is available free of charge via the Internet at http://pubs.acs.org.
} 
ligand buffering in vivo while continuing to provide the advantages of a readily engineered protein framework for tuning analyte binding properties.

Electron spin $(S)$ is a critical factor governing the proton relaxivity of metal ion complexes. ${ }^{7}$ BM3h variants contain a porphyrin-bound ferric ion, which is thought to exist primarily in a low-spin $(S=1 / 2)$ state. We therefore sought to increase the relaxivity of BM3h by replacing the native heme with a protoporphyrin IX (PPIX) complex containing a higher-spin $(S=2)$ $\mathrm{Mn}^{3+}$ ion.

Classical strategies for generating porphyrin-substituted heme proteins are based on often cumbersome refolding protocols and are generally impractical on the moderate- to highthroughput scale demanded by protein engineering applications. More recent approaches require the use of specialized bacterial strains and can involve restrictive growth conditions. ${ }^{8-10}$ We found that porphyrin-substituted BM3h variants could be expressed in high yield under conventional culture conditions in a typical Escherichia coli BL21 strain by coinducing expression of the gene of interest with the E. coli $\mathrm{O} 157: \mathrm{H} 7$ outer-membrane heme transporter ChuA. ${ }^{11-13}$ Cells cotransformed with both BM3h- and ChuA-encoding plasmids were grown in supplemented M9 minimal medium and induced in the presence of Mn-PPIX (Figure 1A). Purified manganic protein yields of $20-30 \mathrm{mg} / \mathrm{L}$ of batch culture were easily obtained.

$\mathrm{Mn}^{3+}$-substituted and native iron-containing proteins showed identical mobilities in nondenaturing gel electrophoresis (Figure 1A inset) and identical circular dichroism spectra (Figure 1B inset), suggesting that the manganic and native ferric species are similarly folded. Purified manganic BM3h (Mn-BM3h) exhibited a broad Soret band with $\lambda_{\max }=386$ $\mathrm{nm}$, consistent with thiolate ligation of the manganic ion ${ }^{14}$ and distinct from both ferric BM3h and free Mn-PPIX (Figure S1 in the Supporting Information). Despite functional heme biosynthesis machinery in expression cells, inductively coupled plasma atomic emission spectroscopy confirmed that $>95 \%$ of the purified metalloprotein contained manganese. To demonstrate the generality of the ChuA-based BM3h porphyrin substitution technique for diverse potential applications, diamagnetic $\mathrm{Co}^{3+}$ - and $\mathrm{Zn}^{2+}$-containing PPIX species were also inserted in separate trials. Each gave rise to a species with a distinct UVvis absorbance spectrum (Figure 1B and Table S1 in the Supporting Information).

Mn-BM3h exhibited a $T_{1}$ longitudinal relaxivity of $2.6 \pm 0.1 \mathrm{mM}^{-1} \mathrm{~s}^{-1}$ at $23{ }^{\circ} \mathrm{C}$ and $4.7 \mathrm{~T}$, a 2-fold improvement over the native ferric BM3h $r_{1}$ of $1.3 \pm 0.1 \mathrm{mM}^{-1} \mathrm{~s}^{-1}$ (Figure 2A). The relaxivity of Mn-BM3h peaked at lower field, and the greatest absolute $r_{1}$ difference between the manganic and ferric proteins was observed at 1.0 T. The Mn-BM3h relaxivities were also comparable to $r_{1}$ values recorded at similar field strengths for other Mn-PPIXsubstituted refolded proteins. ${ }^{15}$ Despite the structural perturbation expected upon metal substitution, ${ }^{16} \mathrm{Mn}$-BM3h was slightly more stable than native BM3h. The variants have thermal denaturation midpoint temperature $\left(T_{50}\right)$ values of 54.6 and $51.9^{\circ} \mathrm{C}$, respectively, as measured using $10 \mathrm{~min}$ incubation periods (Figure S2). ${ }^{17}$

To test the potential of Mn-BM3h to act as a ligand-dependent responsive contrast agent, we examined its relaxivity change in the presence of arachidonic acid (AA), a natural ligand shown to decrease $r_{1}$ by $66 \%$ upon binding to native BM3h. ${ }^{6}$ While optical titration (Figure S3) indicated that AA could bind to Mn-BM3h with a dissociation constant $\left(K_{\mathrm{d}}\right)$ of $0.7 \pm 0.5$ $\mu \mathrm{M}$, we found that the $r_{1}$ of wild-type Mn-BM3h changed by only $1.1 \%$ upon AA binding.

Proteins with improved basal relaxivity, stability, and ligand responsiveness were observed from among a further set of $\mathrm{Mn}^{3+}$-substituted BM3h variants. The collection included a recently reported variant engineered for dopamine sensing by $\mathrm{MRI}^{6}$ and five thermostable chimeric P450 domains identified previously from a library of artificially recombined BM3h 
homologues ${ }^{17}$ (Table S2). Diverse combinations of $r_{1}$ and $T_{50}$ were observed among the manganic variants (Figure 2B), indicating that both parameters can be tuned by mutagenesis of the Mn-BM3h platform.

The $\mathrm{Mn}^{3+}$-containing proteins with the highest relaxivities and stabilities comparable to or better than wild-type Mn-BM3h were titrated with AA to determine the corresponding $K_{\mathrm{d}}$ values and relaxivity changes upon binding. A variant called Mn-C1634 displayed the best combination of properties, with a relaxivity of $3.3 \pm 0.2 \mathrm{mM}^{-1} \mathrm{~s}^{-1}$, a $T_{50}$ value of $56.0 \pm 0.1$ ${ }^{\circ} \mathrm{C}$, and an AA dissociation constant of $2.5 \pm 0.7 \mu \mathrm{M}$. AA binding resulted in a $63 \pm 2.5 \%$ decrease in $r_{1}$ and could be visualized by optical absorbance changes or MRI (Figure 2C,D). Mn-C1634 also exhibited modest $T_{2}$ relaxivity $\left(r_{2}\right)$ averaging $7.4 \pm 0.3 \mathrm{mM}^{-1} \mathrm{~s}^{-1}$ over the AA concentration range (Figure S4). Several potential competitors with structural similarity to AA showed substantially less binding to Mn-C1634 (Figure S5). These optical and MRI results indicate that Mn-C1634 could be useful for imaging-based detection of AA in tissue culture or living organisms, where AA is a key component of inflammatory signaling and reaches concentrations as high as $100 \mu \mathrm{M}$ in some contexts. ${ }^{18}$

The AA-dependent relaxivity change from 3.3 to $1.2 \mathrm{mM}^{-1} \mathrm{~s}^{-1}$ in Mn-C1634 is greater by a factor of 2.4 than the $\Delta r_{1}$ values exhibited by first-generation ferric BM3h-based MRI sensors and also comparable to high-field relaxivity changes reported in the literature for synthetic $\mathrm{Gd}^{3+}$-based responsive contrast agents. ${ }^{1}$ Through a combination of ChuAmediated metal substitution and traditional protein engineering techniques applied to BM3h, it could be possible to access further gains in relaxivity as well as alterations of ligand specificity and other properties. The present work demonstrates more generally that metal substitution techniques can be an important component of efforts to engineer effective protein-based sensors for molecular MRI.

\section{Supplementary Material}

Refer to Web version on PubMed Central for supplementary material.

\section{Acknowledgments}

We thank Joseph Frank and L. Henry Bryant for help with NMRD measurements and Mikhail Shapiro and Fay Bi for helpful discussions. This work was supported by NIH Grant R01-DA28299 to A.J. and a Caltech Jacobs Grant to F.H.A. E.B. was supported by an NIH NRSA Fellowship (Award F32-GM087102).

\section{REFERENCES}

(1). Jasanoff A. Curr. Opin. Neurobiol. 2007; 17:593-600. [PubMed: 18093824]

(2). Lelyveld VS, Atanasijevic T, Jasanoff A. Int. J. Imaging Syst. Technol. 2010; 20:71-79. [PubMed: 20808721]

(3). Sun PZ, Schoening ZB, Jasanoff A. Magn. Reson. Med. 2003; 49:609-614. [PubMed: 12652529]

(4). Ogawa S, Lee T, Kay A, Tank D. Proc. Natl. Acad. Sci. U.S.A. 1990; 87:9868-9872. [PubMed: 2124706]

(5). Vymazal J, Zak O, Bulte JW, Aisen P, Brooks RA. Magn. Reson. Med. 1996; 36:61-65. [PubMed: 8795021]

(6). Shapiro MG, Westmeyer GG, Romero PA, Szablowski JO, Küster B, Shah A, Otey CR, Langer R, Arnold FH, Jasanoff A. Nat. Biotechnol. 2010; 28:264-270. [PubMed: 20190737]

(7). Solomon I. Phys. Rev. 1955; 99:559-565.

(8). Winter MB, McLaurin EJ, Reece SY, Olea C, Nocera DG, Marletta MA. J. Am. Chem. Soc. 2010; 132:5582-5583. [PubMed: 20373741]

(9). Woodward JJ, Martin NI, Marletta MA. Nat. Methods. 2007; 4:43-45. [PubMed: 17187078]

(10). Brugna M, Tasse L, Hederstedt L. FEBS J. 2010; 277:2663-2672. [PubMed: 20553500] 
(11). Richard-Fogal CL, Frawley ER, Feissner RE, Kranz RG. J. Bacteriol. 2007; 189:455-463. [PubMed: 17085564]

(12). Varnado CL, Goodwin DC. Protein Expression Purif. 2004; 35:76-83.

(13). Villarreal DM, Phillips CL, Kelley AM, Villarreal S, Villaloboz A, Hernandez P, Olson JS, Henderson DP. Appl. Environ. Microbiol. 2008; 74:5854-5856. [PubMed: 18676700]

(14). Gelb MH. Proc. Natl. Acad. Sci. U.S.A. 1982; 79:5758-5762. [PubMed: 6964386]

(15). Gupta R, Mildvan A, Schonbaum G. Arch. Biochem. Biophys. 1980; 202:1-7. [PubMed: 7396528]

(16). Makris TM, von Koenig K, Schlichting I, Sligar SG. J. Inorg. Biochem. 2006; 100:507-518. [PubMed: 16510191]

(17). Li Y, Drummond DA, Sawayama AM, Snow CD, Bloom JD, Arnold FH. Nat. Biotechnol. 2007; 25:1051-1056. [PubMed: 17721510]

(18). Brash AR. J. Clin. Invest. 2001; 107:1339-1345. [PubMed: 11390413]

$J$ Am Chem Soc. Author manuscript; available in PMC 2011 August 10. 

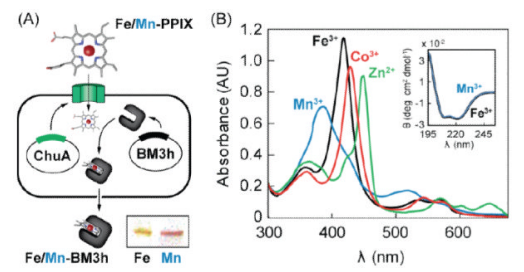

Figure 1.

Formation and characterization of purified metalloporphyrin-substituted cytochrome P450 BM3h proteins. (A) Schematic showing recombinant expression of metal-substituted BM3h species in E. coli coexpressing BM3h (black) with the ChuA porphryin transporter (green), supplemented with protoporphyrin IX (PPIX) complexes. The gel fragment in the inset at the lower-right indicates equivalent mobilities of purified ferric and manganic BM3h in nondenaturing $7.5 \%$ polyacrylamide gel electrophoresis; the colored bands arise from natural pigmentation of the proteins. (B) Absorbance spectra of purified wild-type BM3h derivatives following coexpression with $\mathrm{ChuA}$ and purification from cultures supplemented with $30 \mu \mathrm{g} / \mathrm{mL} \mathrm{Mn}(\mathrm{III}), \mathrm{Fe}(\mathrm{III}), \mathrm{Co}(\mathrm{III})$, or Zn(II) PPIX complexes. Inset: circular dichroism spectra indicating the similarity of the secondary structures of ferric and manganic $\mathrm{BM} 3 \mathrm{~h}$ in $10 \mathrm{mM}$ potassium phosphate $(\mathrm{pH} 7.4)$ and $100 \mathrm{mM}\left(\mathrm{NH}_{4}\right)_{2} \mathrm{SO}_{4}$. 

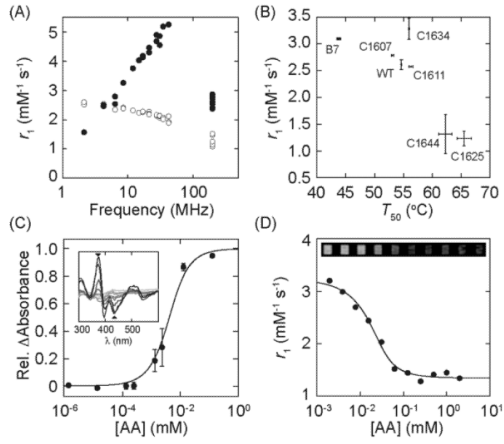

Figure 2.

Longitudinal relaxivity and ligand responsiveness of $\mathrm{Mn}^{3+}$-substituted BM3h proteins. (A) Nuclear magnetic relaxation dispersion profile of wild-type (WT) Mn-BM3h (•) vs native ferric BM3h (०). Points at $200 \mathrm{MHz}$ were measured in a 4.7 T MRI scanner, and the remaining points were obtained using a variable-field relaxometer. (B) Diverse combinations of molar $T_{1}$ relaxivity $\left(r_{1}\right)$ at $4.7 \mathrm{~T}$ and half-maximal 10 min denaturation temperature $\left(T_{50}\right)$ were observed among manganic BM3h variants formed from WT BM3h, the dopamine sensor B7, and thermostable chimeric BM3h homologues (C1607, C1611, C1625, C1634, and C1644). (C) Normalized optical absorbance changes of $5 \mu \mathrm{M}$ Mn-C1634 in PBS as a function of arachidonic acid (AA) concentration. Error bars denote standard errors of the mean $(n=4)$. Data points were computed from difference spectra (inset; higher AA concentrations correspond to darker lines) by subtracting absorbance changes observed at $\lambda=380$ and $430 \mathrm{~nm}$ (arrowheads). (D) Representative longitudinal molar relaxivities $\left(r_{1}\right)$ observed at $4.7 \mathrm{~T}$ during an AA titration into $54 \mu \mathrm{M}$ Mn-C1634 in PBS. The inset shows corresponding spin-echo image data with TR/TE $=1221 / 10 \mathrm{~ms}$. Lines in $\mathrm{C}$ and $\mathrm{D}$ were obtained by fitting the data to a two-component binding model. 